\section{NOTICE OF REDUNDANCY}

The hanging committee of Sexually Transmitted Infections wishes to announce that two published papers by van Valkengoed et $a l^{1}$ exhibit a degree of overlap. Specifically, the female patients are the same in both papers. They are indistinguishable from the point of population size (5714), age (15-40), setting, participation rate $(51 \%)$, chlamydia prevalence rate $(2.8 \%$; CI $2.1-3.4 \%)$, and the number of women excluded because of never having been sexually active (125). There is also a certain degree of overlap between the two papers in the introduction, methods, results, and discussion sections.

1 Van Valkengoed IGM, Boeke JAP, Moore SA, $e$ al. Disappointing performance of literaturederived selective screening criteria for asymptomatic Chlamydia trachomatis infection in an inner-city population. Sex Transm Dis 2000;27:504-7.

2 Van Valkengoed IGM, Morré SA, van den Brule $\mathrm{AJC}$, et al. Low diagnostic accuracy of selective screening criteria for asymptomatic Chlamydia trachomatis infections in the general population. Sex Transm Inf 2000;76:375-80.

\section{Reply}

We strongly disagree with your conclusion that we are guilty of duplicate publication. The objectives, analyses, and results presented in the two papers in Sexually Transmitted Diseases (paper 1) ${ }^{1}$ and Sexually Transmitted Infections (paper 2) ${ }^{2}$ are completely different and do not resemble each other at all. The aim of paper 1 was to determine the value of currently publicised screening criteria for asymptomatic populations as selection criteria for the general population. A literature review was performed to identify criteria for women. Criteria for men were not available. These criteria were then applied to the female participants in the Amsterdam Screening Study. The diagnostic accuracy of these criteria was then found to be poor. That led to the second research question, which was addressed in paper 2: Could suitable new criteria for selective screening of females and males be derived from our own study population? In paper 2 we report on the development of this new set of selective screening criteria and their diagnostic accuracy. In addition, detailed prevalence data and the results for both men and women nonrespondents in the Amsterdam Screening Study were presented.

The papers did not contain references to each other. This was not through intent, but because of the simultaneous process of submission for publication. At the time of submission, there was simply no other "paper" to refer to. When checking the proofs of the papers we should have added "in press" to the references, which we neglected to do. We sincerely apologise for this and will remember to do so in future.

In summary, we believe your verdict of duplicate publication to be unjust and your sanction to be too harsh for the omission of cross references. SERVAAS A MORRÉ
ADRIAAN J C VAN DEN BRULE WALTER DEVILLÉ CHRIS J L M MEIJER LEX M BOUTER

Vrije Universiteit, Amsterdam, Netherlands

1 Van Valkengoed IGM, Boeke AJP, Morre SA, et al. Disappointing performance of literaturederived selective screening criteria for asymptomatic Chlamydia trachomatis infection in an inner-city population. Sex Transm Dis 2000;27:504-7.

2 Van Valkengoed IGM, Morré SA, van den Brule AJC, et al. Low diagnostic accuracy of selective screening criteria for asymptomatic Chlamydia trachomatis infections in the general popula tion. Sex Transm Inf 2000;76:375-80.

\section{LETTERS TO THE EDITOR}

Prevalence of Chlamydia trachomatis IgG antibodies in antenatal patients from Trinidad

EDIToR,-A recent study in Jamaica by Dowe et al using cell culture and a direct fluorescence assay (DFA) showed a prevalence of Chlamydia trachomatis infection in $47 \%$ of gynaecological patients. ${ }^{1}$ Unfortunately, there are no comparable data for cell culture and DFA in Trinidad. Moreover, we cannot find any reports on serological studies for $C$ trachomatis IgG antibody in the West Indies. In an attempt to shed more light on prevalence of $C$ trachomatis IgG antibody in pregnant women in Trinidad, we collected 56 serum specimens (mean age of patients 27 years) with ethics committee approval from one clinic at the general hospital, Port of Spain. As well as testing these sera by an in-house ELISA method based on that described by Ossewaarde $e t a l,{ }^{2}$ we also used a commercial ELISA test specific for $C$ trachomatis IgG (Savyon Diagnostics, Israel) and the whole inclusion immunofluorescence (WHIF) test as previously described by Richmond and Caul.

All collected sera were stored at $-70^{\circ} \mathrm{C}$ until analysis. Samples were subsequently coded and tested blind in duplicate in laboratories in Sheffield and Bristol. Details of the in-house ELISA test methodology and interpretation of readings using microimmunofluorescence (MIF) serum positive and negative controls were described in Keay et $a l^{4}$ The commercial ELISA was performed according to the manufacturer's instructions. The WHIF test consisted of chlamydial inclusions of infected mammalian cells with LGV2 mounted on a glass well or coverslip. The WHIF titre is described as the highest dilution of antibody where the inclusion can be clearly seen by fluorescence staining.

For the ELISA tests, results were recorded as positive, negative, or equivocal. For the WHIF test, titres between 1:64 and 1:256 were recorded as such; a low titre was $\leqslant 1: 64$ and a high titre $\geqslant 1: 512$.

Twenty five (45\%) and $29(52 \%)$ samples were positive for the commercial and inhouse ELISA tests respectively. Eighteen $(32 \%)$ samples had a titre of $\geqslant 512$ in the WHIF test, as shown in table 1 .

The latter finding is of note. It is accepted that $C$ trachomatis is an established pelvic
Table 1 Comparison of ELISA and WHIF tests showing the Chlamydia trachomatis IgG antibody titre distribution

\begin{tabular}{|c|c|c|c|c|c|c|}
\hline \multirow{2}{*}{$\begin{array}{l}\text { WHIF } \\
\text { test }\end{array}$} & \multicolumn{3}{|c|}{$\begin{array}{l}\text { Commercial } \\
\text { ELISA }\end{array}$} & \multicolumn{3}{|c|}{ In-house ELISA } \\
\hline & + & $E q$ & - & + & $E q$ & - \\
\hline$\geqslant 512$ & 15 & 1 & 2 & 18 & - & - \\
\hline 256 & 3 & - & 1 & 3 & 1 & - \\
\hline 128 & 4 & - & - & 2 & 1 & 1 \\
\hline & 2 & - & 4 & 4 & 1 & 1 \\
\hline$\leqslant 64$ & 1 & 1 & 1 & 2 & - & 1 \\
\hline
\end{tabular}

$\mathrm{Eq}=$ equivocal

pathogen and in a recent study of 34 women positive for $C$ trachomatis IgG $(\geqslant 1: 128)$ by ELISA, at laparoscopy $31(91.2 \%)$ were diagnosed as having tubal disease. ${ }^{5}$ It is likely that significant damage could be occurring in these patients as a previous study looking at high $C$ trachomatis IgG titres showed $46 \%$ positive and $8 \%$ positive in infertile women with damaged and normal tubes, respectively. ${ }^{6}$

Although these findings are based on relatively small numbers, they are of significant concern if combined with the other most recent study. ${ }^{1}$ It would appear that the prevalence rates for $C$ trachomatis may well be high and that data presented here suggest possible future PID development and resultant sequelae. It is clear that further studies are warranted and that screening and treatment strategies may be required urgently to curtail considerable morbidity in Trinidad and throughout the West Indies in general.

- High prevalence of $C$ trachomatis IgG antibodies in antenatal patients in Trinidad

- Prevalence rates of $C$ trachomatis in Trinidad are similar to those from Jamaica

- Good correlation of in-house and commercial ELISA tests with WHIF test

- Urgent need for screening and treatment strategies for $C$ trachomatis in West Indies

Financial support was provided by the University of Sheffield and Bristol Public Health Laboratory. A ELEY

H A HEMEG I GEARY

Division of Genomic Medicine, University of Sheffield Medical School, Sheffield S10 2RX, UK S S RAMSEWAK Department of Clinical Surgical Sciences, The University of the West Indies, St Augustine, Trinidad A HERRING E O CAUL

Genitourinary Infections Reference Laboratory, Bristol Public Health Laboratory, Bristol BS2 8EL, UK Correspondence to: Dr A Eley, Division of Genomic Medicine, Floor F, University of Sheffield Medical School, Beech Hill Road, Sheffield S10 2RX, UK

a.r.eley@sheffield.ac.uk

1 Dowe G, Smikle M, King SD, et al. High prevalence of genital Chlamydia trachomatis infection in women presenting in different clinical settings in Jamaica: implications for control strategies. Sex Transm Inf 1999;75:412-6.

2 Ossewaarde JM, de Vries A, van den Hoek JAR, et al. Enzyme immunoassay with enhanced et al. Enzyme immunoassay with enhanced specificity for detection of antibodies to 32:1419-26.

3 Richmond ST, Caul EO. Fluorescent antibody studies in chlamydial infections. $\mathcal{F}$ Clin Microstudies in chlamydial
biol $1975 ; 1: 345-52$ 
4 Keay SD, Barlow R, Eley A, et al. The relation between immunoglobulin $G$ antibodies to Chlamydia trachomatis and poor ovarian response to gonadotrophin stimulation before in vitro fertilisation. Fertil Steril 1998;70:214-8.

5 Gaudoin M, Rekha P, Morris A, et al. Bacterial vaginosis and post chlamydial infection are strongly and independently associated with tubal infertility but do not affect in vitro fertilization success rates. Fertil Steril 1999;72:730-2.

6 Conway D, Glazener CMA, Caul EO, et al. Chlamydial serology in fertile and infertile women. Lancet 1984;1:191-3.

Accepted for publication 17 April 2001

\section{Implications of random measurement error in studies adjusting for sexual behaviours}

EDITOR,-In their recent review of methodological issues in sexual behaviour research, Fenton et $a l^{1}$ provide a comprehensive overview of the major types of sexual behaviour research, the sources of measurement error which may affect such research, and different approaches to measuring various forms of measurement error. We would like to provide an important footnote on the implications of the poor measurement of sexual behaviours for drawing inferences from studies of sexually transmitted infections (STIs) which attempt to adjust for sexual behaviours in their analyses.

The role of systematic measurement errors in study design and analysis, as described by Fenton et al, is widely recognised. Given their impact on inferences of association, great care is taken in most studies to avoid these biases. The effects of random measurement error, or non-differential misclassification, on epidemiological inference typically receive less attention. Most researchers realise that non-differential misclassification of exposure and/or outcome measures will lead to an attenuation of the resulting measure of association.

However, the fact that random measurement error in potential confounding variables may wreak havoc on the inferences which are made from study results is seldom acknowledged. The non-differential misclassification of a dichotomous confounding variable may lead to inadequate statistical adjustment (often referred to as residual confounding) and the false appearance of statistical interaction when none is present. ${ }^{2}$ When confounders are measured as polytomous or continuous variables (for example, condom use never/sometimes/always or number of sexual partners), random measurement error can bias the adjusted measure of association unpredictably - in some instances making the adjusted measure of association less accurate than the crude. ${ }^{3}{ }^{4}$ These forms of misclassification are generally of greatest concern when the true exposure-disease association is relatively weak compared with the exposureconfounder and outcome-confounder relation, ${ }^{5}$ as is the case in most research around STIs. Even small random errors can have major effects on adjusted measures of association, and the unpredictability of the effects of misclassification may be compounded in multivariate analyses.

With this in mind, Fenton et al's review of the difficulties involved in the accurate measurement of sexual behaviour has powerful implications for studies attempting to control for covariates associated with risk for STIs. Studies which attempt to adjust during statistical analysis for numbers and types of sexual partners, frequency of sexual contacts, or condom use practices, are likely to encounter some degree of random measurement error. Although perhaps nondifferential with respect to exposure or outcome, this mismeasurement may lead to unpredictable biases and/or mis-specified analyses, and in turn, spurious inferences.

In summary, the inadequate measurement of sexual behaviour requires special consideration in any study attempting to adjust for the confounding role of sexual behaviours in associations involving STIs. We hope that Fenton et al's review of the challenges posed by the collection of sexual behaviour data helps to draw attention to this frequently overlooked methodological aspect of the epidemiology of STIs.

LANDON MYER

HIV Prevention and Vaccine Research, South African Medical Research Council, PO Box 658, Hlabisa 3937, South Africa

CHELSEA MORRONI

Women's Health Research Unit, Department of Public Health, University of Cape Town, South Africa

Correspondence to: Landon Myer, Fogarty-AITRP, Division of Epidemiology, School of Public Health, Columbia University, 600 West 168 th Street, PH 18, New York, New York, 10032, USA

Landon.Myer@mrc.ac.za or

landon_myer@hotmail.com

1 Fenton KA, Johnson AM, McManus S, et al. Measuring sexual behaviour: methodological challenges in survey research. Sex Transm Inf 2001;77:84-92.

2 Cox B, Elwood JM. The effect on stratumspecific odds ratios of non-differential misclassification of a dichotomous covariate. $A m \mathcal{F}$ Epidemiol 1991;133:202-7.

3 Wacholder S. When measurement errors correlate with truth: surprising effects of nondifferential misclassification. Epidemiology 1995;6:157-61.

4 Brenner H. Bias due to non-differential misclassification of polytomous confounders. I Clin Epidemiol 1993;46:57-63.

5 Marshall JR, Hastrup JL. Mismeasurement and the resonance of strong confounders: uncorrethe resonance of strong confounders: uncorre-
lated errors. Am $\mathcal{F}$ Epidemiol 1996;143:106978.

6 Phillips AN, Davey G. Bias in relative odds estimation owing to imprecise measurement of correlated exposures. Statistics in Medicine 1992;11:953-61.

Accepted for publication 22 May 2001

\section{Is Mycoplasma hominis a vaginal pathogen?}

EDITOR,-We would like to comment on the study by Arya and colleagues ${ }^{1}$ in which they failed to find evidence for Mycoplasma hominis being pathogenic in the vagina, or otherwise contributing to bacterial vaginosis (BV). They mentioned the 21 year old review of Taylor-Robinson and McCormack ${ }^{2}$ who surmised that $M$ hominis might act in symbiosis with other organisms or as a sole pathogen in BV. The latter was referred to as non-specific vaginitis or Gardnerella associated vaginitis at that time, the term BV being used from about 1984. Since then, much has been learned about the vaginal microflora in health and disease, but the question of which bacteria, if indeed any, cause BV remains unanswered. The few $M$ hominis organisms in the healthy vagina appear to behave as commensals. We challenged ${ }^{3}$ the suggestion of Mårdh and colleagues that $M$ hominis was associated with a number of genital signs and symptoms after BV had been excluded, our assertion being that $M$ hominis organisms outside the context of BV would be present in small numbers and, therefore, unlikely to cause a problem. In contrast, the few $M$ hominis organisms in the healthy vagina increase in number, perhaps by 10000 -fold or more, in the vagina of women with BV. This increase, however, occurs only late in the development of $\mathrm{BV} .{ }^{4}$ Indeed, it is rare to find large numbers in the "intermediate" (grade 2 ) stage between the normal vaginal flora and "full blown" BV (grade 3). Thus, in the study by Arya and colleagues we have difficulty in understanding why only $35(48 \%)$ of the 73 women with $M$ hominis positive BV had large numbers of organisms $\left(>5 \times 10^{5}\right)$. A Gram stain evaluation should have distinguished women with grade 2 flora from those with grade 3 . Be this as it may, the authors contend that because the additional presence of $M$ hominis with $G$ vaginalis and strict anaerobes did not seem to increase the likelihood of the women developing $\mathrm{BV}, M$ hominis is not involved. It is clear that $M$ hominis organisms are not essential for the development of BV and unlikely that their initial presence in the vagina increases the likelihood of BV developing. However, if they are present in the vagina initially, then they will multiply as indicated and large numbers will ensue. The data of Arya and colleagues do not resolve the issue of whether large numbers contribute to the disease process or are involved in its persistence. Against this, as they point out, is a study $^{5}$ in which metronidazole, inactive in vitro against $M$ hominis, cleared vaginitis, and doxycycline, active against $M$ hominis, did not. However, it should also be remembered that $M$ hominis organisms caused pharyngitis and cervical lymphadenopathy when given orally in large numbers to volunteers, ${ }^{6}$ indicating the pathogenic potential of the organisms. Furthermore, the $M$ hominis species is heterogeneous, some strains having greater epithelial cell adherence properties than others. We do not see any data that point to $M$ hominis being a sole pathogen or co-pathogen in the vagina but, equally, we are not convinced by data that purport to show that it is not.

DAVID TAYLOR-ROBINSON

Department of Genitourinary Medicine, Imperial College School of Medicine, St Mary's Hospital, Paddington, London W2 1NY, UK ISOBEL J ROSENSTEIN Scientific Development Division, Public Health Laboratory Service, Headquaters Office, 61 Colindale Avenue, London NW9 5DF, UK

1 Arya OP, Tong CYW, Hart CA, et al. Is Mycoplasma hominis a vaginal pathogen? Sex Transm Inf 2001;77:58-62.

2 Taylor-Robinson D, McCormack WM. The genital mycoplasmas. $N$ Engl f Med 1980;302: 1003-10.

3 Taylor-Robinson D, Rosenstein I. Vaginal flora changes associated with Mycoplasma hominis. Am J Obstet Gynecol 1998;178:415-6.

4 Rosenstein IJ, Morgan DJ, Sheehan M, et al. Bacterial vaginosis in pregnancy-distribution of bacterial species in different Gram stain categories of the vaginal flora. $7 \mathrm{Med}$ Microbiol 1996; $45: 120-6$.

5 Pheifer TA, Forsyth PS, Durfee MA, et al. Nonspecific vaginitis: role of Haemophilus vaginalis Med 1978;298:1429-34.

6 Mufson MA, Ludwig WM, Purcell RH, et al. Exudative pharyngitis following experimental Mycoplasma hominis type 1 infection. $\mathcal{F} \mathrm{Am}$ Med Assoc 1965;192:1146-52.

Accepted for publication 10 May 2001

Response of hepatitis B induced membranoproliferative glomerulonephritis to HAART

EDITOR,- - Renal disease occurring in HIV infected individuals is well described. ${ }^{12} \mathrm{HIV}$ associated nephropathy (HIVAN) is the 
predominant renal lesion in black patients, whereas immune complex and membranous nephropathy occur more commonly in white patients. ${ }^{1}$ Improvements in renal function have been described with highly active antiretroviral therapy (HAART) when the underlying renal lesion is HIVAN or membranous nephropathy. ${ }^{3-5}$ We report here an HIV infected patient in whom renal disease caused by hepatitis $B$ induced membranoproliferative glomerulonephritis improved with HAART.

A 34 year old white homosexual man was found to be HIV-1 antibody positive in August 2000 after he presented with biopsy proved Kaposi's sarcoma. At this time he also reported 2 months of fatigue and frothy urine. In the past he had been found to be hepatitis BeAg positive in 1996. Examination revealed multiple cutaneous Kaposi's sarcoma, $\mathrm{BP}=170 / 100$, no peripheral oedema, and scanty retinal haemorrhages on funduscopy. Investigations showed blood urea $=9.2$ (normal $=2.8-7.6) \mathrm{mmol} / \mathrm{l}$, serum creatinine $=178($ normal $=80-133) \mu \mathrm{mol} / 1$, normal serum, potassium, and sodium. Liver function tests were normal apart from a serum albumin of 29 (normal $=35-50) \mathrm{g} / \mathrm{l}$. The haemoglobin was $9.3 \mathrm{~g} / \mathrm{dl}$ and white blood cell and platelet counts were normal. The CD 4 count was 110 cells $\times 10^{6} / 1$ and HIV viral load was 47500 copies $/ \mathrm{ml}$. Complement C3 was 0.56 (normal $=0.9-1.8) \mathrm{g} / \mathrm{l}, \mathrm{C} 4$ was 0.07 (normal $=0.1-0.4) \mathrm{g} / \mathrm{l}$. Immunoglobulin quantification showed normal IgA, IgG = $23.2($ normal $=7.0-16.0) \mathrm{mg} / \mathrm{l}$ and $\mathrm{IgM}=$ 4.4 (normal $=0.4-2.3$ ) $\mathrm{g} / \mathrm{l}$. Hepatitis $\mathrm{B}$ serology showed HbeAg+ and HbsAg+ (titre 1:3200). Urinalysis showed blood +++ and ++++ protein. Urine protein $=5.8 \mathrm{~g} / 24$ hours and creatinine clearance $=66 \mathrm{ml} / \mathrm{min}$. Ultrasound examination showed normal sized kidneys. Histology of a renal biopsy showed membranoproliferative glomerulonephritis. Staining showed marked deposits of hepatitis B core and surface antigens (fig 1).

The patient was managed conservatively. HAART was commenced with efavirenz, didanosine, and stavudine and hypertension was treated with ramipril. After 8 weeks of HAART the CD4 count was 140 cells $\times 10^{6} / 1$ and viral load was 100 copies $/ \mathrm{ml}$. The serum creatinine returned to normal and there was no persistent proteinuria.

This case illustrates the importance of considering non-HIV associated pathology in the HIV infected patient presenting with renal disease. It also shows the value of renal

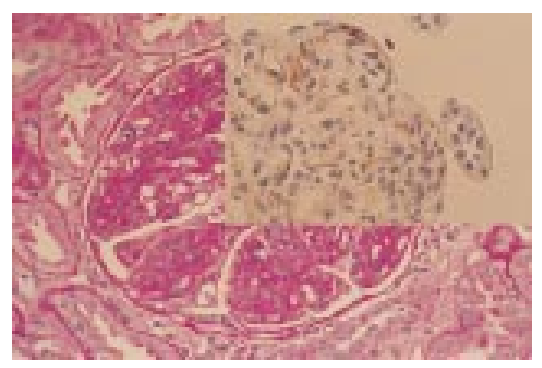

Figure 1 Renal histology shows glomerular mesangial expansion and thickening of the capillary walls, characteristic of membranoproliferative glomerulonephritis. The mesangial areas and capillary walls were positive for $\operatorname{IgG}, \operatorname{IgA}, \operatorname{Ig} M$, and complement components $C 3$ and $C 1 q$. There was also positive staining for hepatitis $B$ surface and core (inset) antigens. Haematoxylin and eosin $\times 400$ and immunoperoxidase $\times 400$ (inset). biopsy in identifying the precise cause of the presentation. This patient demonstrates that non-HIV hepatitis B associated renal disease may improve with HAART. The exact mechanism for this remains unclear.

A SMITH

D CARTLEDGE

H GRIFFITHS

R F MILLER

Department of Sexually Transmitted Diseases, Royal Free and University College Medical School, Mortimer Market Centre, London WC1E 6AU, UK

Correspondence to: Dr Miller

rmiller@gum.ucl.ac.uk

1 Williams DI, Williams DJ, Williams IG, et al. Presentation, pathology and outcome of HIV associated renal disease in a specialist centre for associated renal disease in a specialist centre for

2 Nochy D, Glotz D, Dosquet P, et al. Renal disease associated with HIV infection: a multicentre study of 60 patients from Paris hospitals. Nephrol Dial Transplant 1993;8:11-19.

3 Wali RK, Drachenburg CI, Papadimitrou JC, et al. HIV-associated nephropathy and response to highly active antiretroviral therapy. Lancet 1998;352:783-4.

4 Dellow E, Unwin R, Miller R, et al. Protease inhibitor therapy for HIV infection: the effect on HIV-associated nephrotic syndrome. Nephrol Dial Transplant 1999;14:744-7.

5 Dellow E, Unwin R, Miller R. Presentation, diagnosis and management of renal failure in patients with HIV infection. AIDS Patient Care STDs 2000;14:71-2.

\section{Cervical cytology smears in sexually} transmitted infection clinics in the United Kingdom

EDITOR,-I found the article by Janet Wilson and Wendy Parsons on behalf of the BCCG, concerning cervical cytology practice in UK genitourinary medicine clinics, comprehensive and reassuring in terms of our practice. ${ }^{1}$

The final statement "there is therefore no evidence from this study to support the practice of additional smears in the presence of an effective national cytology screening programme" is both justified and a case well made.

The paper calls additional smears "opportunistic" and recognises them as being performed in women less than the age of 20, women with genital warts, and in some who have had a normal smear within the previous 3 years.

The $O E D$ definition of opportunity is "favourable, appropriate or advantageous combination of circumstances." ${ }^{2}$ There is no evidence to suggest that offering smears in these circumstances fulfils this description. If this is so, then we are depriving women such as teenagers of a valuable health screen and patently this is not the case.

I would like to propose, therefore, that we no longer continue to call these smears "opportunistic" but use the term "unnecessary.”

The recognition of this could be an advance for evidence based practice, help to reduce unnecessary anxiety, and release much needed resources.

D A HICKS

Department of Genitourinary Medicine, Sheffield Teaching Hospitals, Royal Hallamshire Hospital, Glossop Road, Sheffield S10 2fF, UK

1 Wilson JD, Parsons W, on behalf of the British Co-operative Clinical Group. Cervical cytology
smears in sexually transmitted infection clinics in the United Kingdom. Sex Transm Inf 2001;77:107-10
2 Collins Oxford English Dictionary. Ed Patrick Hanks. London and Glasgow: Collins, 1999.

Accepted for publication 22 May 2001

\section{BOOK REVIEW}

The Wages of Sin. Sex and Disease, Past and Present. By P L Allen. £17.50; pp 202. Chicago: University of Chicago Press, 2000. ISBN 0226014606.

This is a profound work describing the impact of venereal diseases and conventional morality in the build up to AIDS. It is written by an American, who has been personally affected by the impact of AIDS. He has written a book on topics in history relating to sex, morality, and infectious diseases, which have had an impact on the public response to AIDS. Throughout, one senses the author's very real loss in what to him and many others have been tragic times.

It is interesting to see how different the general public moral climate is in different societies in the developed world. Thankfully, some forms of evangelism do not have the same influence everywhere.

Does the historical part of the book tell the medical historian anything new? The answer is yes. And that is the gap between what has been known on this subject to academics for a long time and what others are only finding out about now. The chapters containing information on the church's attitude to sexual morality; on leprosy, the early history of syphilis, bubonic plague, and masturbation illustrate the age old story of reactionary view against progress. It is difficult to judge the mores of the past through the views of the present.

It is a pity that the author seems to have given such prominence to those whose views resisted progress. Nothing is mentioned of liberal pioneers in venereal diseases from Van Swieten in the 18th century, through Ricord, Fournier in the next, Abraham Flexner (for the Rockerfeller Foundation), Neisser, or indeed the enormous changes brought about by the Royal Commission on Venereal Diseases in Great Britain at the time of the first world war or such notable more recent Americans such as Kampmeier, Stokes, or Earl Moore.

The chapters on America are particularly interesting from a European point of view. Learning about reactionary views always helps in developing any strategy for public knowledge and education. Well educated AIDS lobbyists have certainly had an impact in Europe as in the United States and are neatly described in this work. The bibliography, 14 pages, is particularly good.

This is a book questioning responses and conventional morality in respect, sorrow, and anguish. It is worthy of merit. It enables the modern reader to learn about difficult aspects of morality in relation to venereal diseases and sexuality which have always had more impact on the public than the practising physician. 


\section{NOTICES}

International Herpes Alliance and International Herpes Management Forum

The International Herpes Alliance has introduced a website (www.herpesalliance.org) from which can be downloaded patient information leaflets. Its sister organisation the International Herpes Management Forum (website: www.IHMF.org) has launched new guidelines on the management of herpesvirus infections in pregnancy at the 9th International Congress on Infectious Disease (ICID) in Buenos Aires.

Pan-American Health Organization, regional office of the World Health Organization

A catalogue of publications is available online (www.paho.org). The monthly journal of PAHO, the Pan American Journal of Public Health, is also available (subscriptions: pubsvc@tsp.sheridan.com).

1st Asia Pacific Forum on Quality Improvement in Health Care

The 1st Asia Pacific Forum on Quality Improvement in Health Care will be held from 19-21 September 2001 in Sydney, Australia. Presented by the BMJ Publishing Group (London, UK) and Institute for Healthcare Improvement (Boston, USA), with the support of the Commonweatlh
Department of Health and Aged Care (Australia), Safety and Quality Council (Australia), NSW Health (Australia) and Ministry of Health (New Zealand). Further details: quality@bma.org.uk; fax $\quad+44$ (0) 7383 6869 .

41st St Andrew's Day Festival Symposium on Therapeutics

The 41 st St Andrew's Day Festival Symposium on Therapeutics will be held on 6-7 December 2001 at the Royal College of Physicians of Edinburgh. Further details: Ms Eileen Strawn, Symposium Co-ordinator (tel: 0131225 7324; fax: 0131220 4393; email: e.strawn@rcpe.ac.uk; website: www. rcpe.ac.uk).

10th International Congress on Behcet's Disease will be held in Berlin 27-29 June 2002

Further details: Professor $\mathrm{Ch}$ Zouboulis (email: zoubbere@zedat.fu-berlin.de).

5th World Congress of Perinatal Medicine, 23-27 September 2001, Palau de Congressos de Barcelona - Avda Maria Cristina s/n, Barcelona, Spain

Further details: Dr Francesc Figueras, Congress Promotion Secretary (fax: +34.93.451.74 38; website: www. perinatology2001.com).

Second International Conference on Sexual Health, to be held in Bangkok, Thailand on 23-28 February 2002. Calls for abstracts deadline 1 September 2001
Further details: European Secretariat, Dr Richard Burack (tel: +44 (0) 208599 8029; email: siamcare@aol.com).

International Conference on HIVIAIDS 16-19 December 2001, Mumbai, India Further details: Dr Chander P Puri, President, Indian Society for Study of Reproduction and Fertility, Institute for Reserach in Reproduction, Jehangir Merwanji Street, Parel, Mumbai 400012, India (Tel: 4137730 (Direct), 4132111-2-6-7; fax: 091-022-4964853 or 091-022-4139412; e-mail: vichin@, bom4.vsnl.net.in OR dirirr@vsnl.com).

10th International Symposium on Human Chlamydial Infection, 16-21 June 2002, in Antalya, Turkey

The scientific programme will encompass the breadth of chlamydial research from clinical and epidemiological studies to molecular and cell biology of all species of Chlamydia. Further details: Professor A Demir Serter, Department of Clinical Microbiology and Infectious Diseases, Ege University, Faculty of Medicine, 35100 Bornova, Izmir, Turkey (Fax: 9023234371 30; e-mail: ISHCIX@ itsa.ucsf.edu).

20th World Congress of Dermatology, Paris, 1-5 July 2002

Further details: P Fournier, Colloquium, 12 rue de la Croix St Faubin, 75011 Paris, france (rel: +33 1446415 15; fax: +33144641516; email: p.fournier@ colloquium.fr; website: www.derm-wcd2002.com).

Mechanics for Africa-training school in Africa to bring health awareness into curriculum

Mechanics for Africa is a training school for motor mechanics in Zambia, giving young Africans skills for life. This charitable initiative was recently launched to help impoverished Africans break out of the persistent reliance on outside aid to help them become self reliant. Mechanics for Africa (MFA) will set up a school for motor mechanics in Ndola, Zambia, in association with Milford Baptist Church in Surrey. MFA (charity registration No 1086333) was launched recently by its patron, the Rt Hon Virginia Bottomley, MP.

Part of the holistic curriculum will help introduce the need for health awareness among ordinary local people, particularly with HIV/AIDS and other STDs, diarrhoea and resultant dehydration. Other topics to be covered will include malaria (still the biggest killer, especially among children), nutrition, first aid, hygiene, etc. All this to be part of a balanced "life skills" curriculum which will empower students to improve their lives; and those of their families by inviting them to participate in these studies.

The project asks companies, organisations, and individuals to become financially involved at various levels either through donation, tax reclaimable gifts, or loans.

MFA is the brainchild of Charles and Sharonne Watt who have worked on aid projects in southern Africa for 3 years and had the opportunity to evaluate the needs of local and wider communities.

Apart from offering a 2 year course in motor mechanics and maintenance-leading to an internationally recognised City and Guilds qualification - the aim of the project is to offer a balanced curriculum including health education and basic business administration.

Land and property for training and workshop development has already been purchased on the outskirts of Ndola (population 500 000) in the heart of Zambia's copperbelt.

The MFA project is designed to eventually become self funding with a commercial service for vehicle maintenance planned to operate independently and in tandem with the charity.

Mechanics for Africa is actively seeking funds and donations. Further details: Mechanics for Africa, Bridian Farm, Alford, Surrey GU6 8HR, UK (tel: 01403752 384; fax: 01483421 271; email: charlie,sharonne@bigfoot.com; web: www.mfazambia.com). 